\title{
Heterozygosity and morphological variability of chum salmon (Oncorhynchus keta) in southern British Columbia
}

\author{
Terry D. Beacham and \\ Ruth E. Withler
}

\author{
Department of Fisheries and Oceans, Fisheries \\ Research Branch, Pacific Biological Station, \\ Nanaimo, B.C., Canada V9R 5K6.
}

\begin{abstract}
We compared variability in two meristic and six morphometric characters with heterozygosity within and among 27 populations of chum salmon (Oncorhynchus keta) in southern British Columbia. Among individuals, there was no relationship between levels of heterozygosity at $\mathbf{1 0}$ electrophoretic loci and degree of meristic or morphometric variation. Decreased morphological variance was not associated with increased heterozygosity. Morphological variance and heterozygosity did not change with age for chum salmon maturing at three to five years of age. Among populations of chum salmon, increased levels of average heterozygosity were not associated with decreased variance of morphometric or meristic characters. Our results do not support the hypothesis that more heterozygous individuals show less phenotypic variability than more homozygous ones due to a canalisation of morphology during development.

Genetic distances between pairs of chum salmon populations were significantly correlated with pairwise Mahalanobis distances derived from meristic, but not from morphometric characters. Chum salmon are morphometrically adapted to the natal stream environment, whereas biochemical and meristic characters in these populations may be less affected by local selective forces.
\end{abstract}

\section{INTRODUCTION}

The relationship between genetic variance and phenotypic variance has been a topic of concern for several decades. Lerner (1954) suggested that in animals morphological variability is dependent in part on the degree of heterozygosity. Individuals that are heterozygous at many structural loci, or fewer regulatory loci, may be better able to moderate the effects of environmental variability than those that are predominantly homozygous, possibly by maintaining enzymatic activity and regulation of that activity over a wider range of physiological and environmental conditions (Koehn, 1970). The homeostatic advantage (Johnson, 1977) during development of heterozygous over homozygous individuals may be reflected in decreased phenotypic variability.

The widespread use of electrophoresis to examine allozymic variability among and within populations allows testing of the hypothesis that individuals heterozygous at one or many loci have less morphological variance than those homozygous at the same loci. Mitton (1978), working on the fish Fundulus heteroclitus, Eanes (1978) working on the monarch butterfly Danaus plexippus, and Angus and Schultz (1983), working on the fish Poeciliopsis lucida, all provided evidence to suggest that among individuals, morphological variability is inversely related to heterozygosity. Soule (1979) reported a negative correlation between heterozygosity and the degree of asymmetry in populations of lizards. Conversely, Handford (1980) found that heterozygosity was unrelated to morphological variance for a sparrow Zonotrichia capensis, as did McAndrew et al. (1982) for plaice Pleuronectes platessa, and Yoshiyama and Sassaman (1983) for the stichaeid fish Anoplarchus purpurescens. No consistent relationship between morphological variability and genetic heterozygosity is thus apparent in vertebrate populations.

If heterozygosity does confer a developmental homeostasis that is selectively advantageous to individuals within a population, more homozygous 
individuals may show increased morphological variability and, on average, be further from the phenotypic mean of the population than heterozygous ones. Under these conditions, the action of stabilising selection would be a concurrent reduction of phenotypic variability and an increase in heterozygosity with age in the population. Among populations, higher values of average heterozygosity should result in decreased levels of morphological variability.

We investigated these topics by sampling spawning populations of chum salmon (Oncorhynchus keta) in southern British Columbia, Canada and comparing the degree of meristic and morphometric variability with enzymatic variability among individuals and populations. We also examined the relationship between biochemical and morphological variation in chum salmon by comparing genetic distance with Mahalanobis distances for morphometric and meristic characters on a pairwise basis between populations. Chum salmon in southern British Columbia return to spawn and die in their natal streams at 3 to 5 years of age (Ricker, 1980; Beacham and Starr, 1982).

\section{MATERIALS AND METHODS}

Chum salmon stocks from different rivers in southern British Columbia were sampled in 1982 and 1983. The 27 stocks surveyed are outlined in fig. 1. Details of the field sampling procedure have been outlined by Beacham et al. (1983). Summarised briefly, postorbital-hypural length (Vladykov, 1962) was recorded with a hypural stick to the nearest $\mathrm{mm}$. Meristic characters counted were the number of gillrakers on the left most anterior gill arch and the number of branchiostegal rays on the left ventral side of the head. Morphometric characters measured to the nearest $\mathrm{mm}$ with vernier calipers were postorbital head length (Vladykov, 1962), caudal peduncle depth, and base length and height of the anal and dorsal fins (Hubbs and Lagler, 1958). The sex of each individual was confirmed by internal inspection. Ages of chum salmon were determined from scales (Bilton and Ricker, 1965; LaLanne and Safsten, 1969).

Chum salmon were scored as homozygous or heterozygous at each of eight single and two duplicated loci. Isocitrate dehydrogenase (IDH-1), malate dehydrogenase (MDH-1,2; MDH-3,4) malic enzyme (ME), 6-phosphogluconate dehydrogenase (6-PG), alphaglycerophosphate dehydrogenase (AGP-1), and a peptidase (LGG) which utilises leucyl-glycol-glycine as a substrate were scored electrophoretically from muscle tissue. The extremely low levels of heterozygosity observed at the duplicated MDH loci precluded the inclusion of individuals homozygous for alternate alleles at MDH-1,2 or MDH-3,4. AGP-2 was scored from heart tissue. Phosphomannose isomerase (PMI) and IDH-3 were scored from liver tissue. Horizontal starch gel electrophoresis as outlined by Utter et al. (1974) was used to score allozymes.

Size of chum salmon varies among the ages at spawning, among populations, and between the sexes. Morphometric measurements of both males and females were standardised separately to the overall mean postorbital-hypural length of all individuals $(583 \mathrm{~mm})$. This minimized variability as a result of allometric growth and differences in mean size of individuals among populations (Gould, 1966; Thorpe, 1976). We standardized morphometric measurements by the method described by Beacham and Murray (1983). Separate allometric regressions were conducted for each stock and sex combination for each of the six morphometric characters.

We conducted analyses of variance to determine if the means of the meristic and morphometric characters differed among populations, between sexes, and between individuals homozygous and heterozygous at each locus. The model used for the analysis was

$$
\begin{aligned}
Y_{i j k l}= & \mu+A_{i}+S_{j}+H_{k}+A S_{i j}+A H_{i k} \\
& +S H_{j k}+A S H_{i j k}+e_{i j k l}
\end{aligned}
$$

where $\mu=$ mean; $A_{i}=$ effect of the $i$ th population, $i=1,27 ; S_{j}=$ effect of sex, $j=1,2 ; H_{k}=$ effect of heterozygosity, $k=1,2$ (homozygous or heterozygous); $A S_{i j}, A H_{i k}, S H_{j k}, A S H_{i j k}$ are the interactions among the main effects. $e_{i j k l}=$ error term of the $l$ th observation in subgroup $i j k$.

We estimated the within stock variance of each meristic and morphometric character for homozygous and heterozygous individuals separately. Variance was estimated as the residual mean square for the linear model incorporating population and sex as the main effects, along with their interaction.

If two groups of observations have the same population mean but different variances, the average distance between an individual and the population mean must differ between the two groups. We calculated Mahalanobis distance (d) between each individual and its own stock and sex centroid for the meristic and morphometric variables. Mahalanobis distance between an individual 


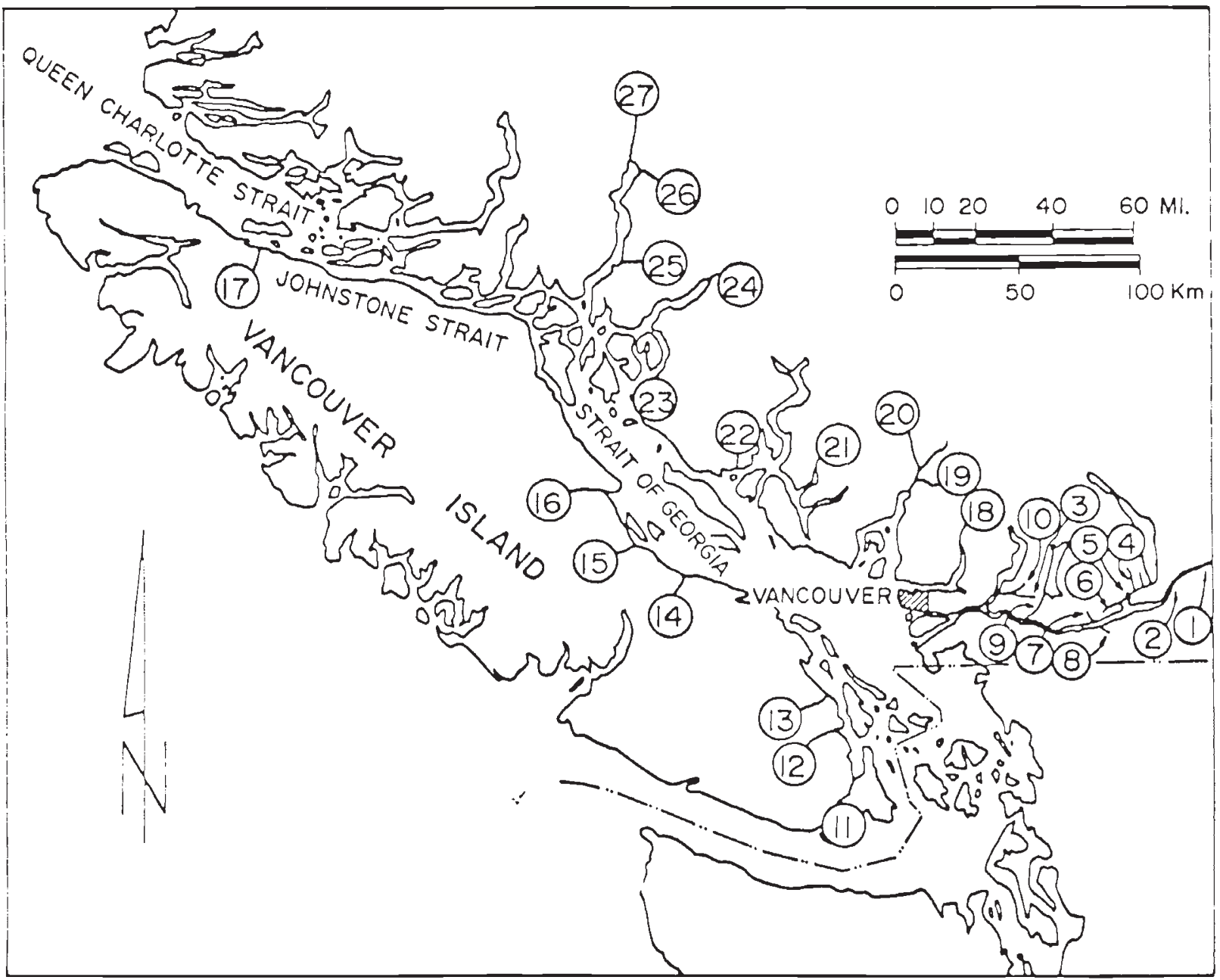

Figure 1 Locations of rivers in southern British Columbia where chum salmon were sampled in 1982 and 1983. Rivers listed in ascending order are: (1) Fraser (2) Wahleach (3) Alouette (4) Chehalis (5) Harrison (6) Squakum (7) Chilqua (8) Vedder (9) Stave (10) Blaney (11) Goldstream (12) Cowichan (13) Chemainus (14) Little Qualicum (15) Rosewall (16) Puntledge (17) Nimpkish (18) Indian (19) Mamquam (20) Squamish (21) Tzoonie (22) Saltery Bay (23) Okeover (24) Toba (25) Orford (26) Southgate (27) Homathko.

(A) and centroid (M) for $p$ variables is (Kendall, 1975):

$$
d^{2}(A M)=\sum_{i=1}^{p}\left(X_{i a}-X_{i m}\right)^{2}
$$

Analyses of variance were then conducted to determine if mean Mahalanobis distance differed among fish homozygous or heterozygous at each locus, or if it varied among fish with different numbers of heterozygous loci. Preliminary analyses indicated that there were no significant stock or sex effects for Mahalanobis distance, so the model tested was

$$
Y_{i j}=\mu+H_{i}+e_{i j}
$$

where $H_{i}=$ effect of number of heterozygous loci, $i=0,5 ; e_{i j}=$ residual variance.

We compared variability in morphometric and meristic characters among populations and mean heterozygosity by comparing the mean coefficient of variation for each set of characters (pooled over all characters in the set) with mean heterozygosity. We used the original unstandardized morphometric measurements in the analysis of the coefficients of variation. The morphometric characters measured have been previously shown to be sexually dimorphic in chum salmon (Beacham, 1984), and thus males and females were analyzed separately. There was no sexual dimorph- 
ism in the meristic characters counted, and thus sexes were combined in the analysis.

We calculated genetic distances between pairs of populations by the method of Nei (1978). We then compared genetic distance between all pairwise combinations of populations with Mahalanobis distance based upon all morphometric characters (sexes separate, standardized measurements) and all meristic characters.

\section{RESULTS}

\section{Individual heterozygosity and morphological variance}

The first step of the analysis was to determine for each locus whether homozygous and heterozygous fish have the same mean values for each meristic and morphometric character. Less than 10 individuals of the 2809 chum salmon examined in this study were heterozygous for each of MDH-1,2, $\mathrm{MDH}-3,4$, or AGP-1, and these loci were excluded from the analyses of variance. Of the 56 analyses of variance conducted (equation (1)) (7 loci by 8 characters) in order to test for differences in mean character values between homozygous and heterozygous fish, none was statistically significant. Therefore, if fish homozygous at any given locus display greater morphological variance than fish heterozygous at that locus, the average Mahalanobis distance (distance to the population centroid) would be greater for homozygotes than for heterozygotes.

We compared within stock variances of each meristic and morphometric character for homozygous and heterozygous fish at each of 6 loci and for all loci combined. The number of heterozygous individuals at the 6-PG locus was too small to provide a meaningful analysis. We tested the hypothesis that homozygous and heterozygous fish had equal variances for each character examined. Of 56 tests conducted, the $F$-statistic was $<1.00$ in 27 cases, equal to 1.00 in 6 cases, and greater than 1.00 in 23 cases (table 1). When considered on a locus by locus and character by character basis, homozygous and heterozygous chum salmon have equal morphological variability.

We compared the average Mahalanobis distance of fish with differing numbers of heterozygous loci to their group mean for each meristic and morphometric character. Chum salmon with more heterozygous loci were not significantly closer to

Table 1 Within stock variances of 2 meristic and 6 morphometric characters for homozygous and heterozygous chum salmon at 6 loci. Equality of the variances was tested by the $F$ statistic

\begin{tabular}{|c|c|c|c|c|c|c|c|c|c|c|}
\hline Locus & State & $N$ & Gillrakers & $\begin{array}{l}\text { Bran- } \\
\text { chiostegal } \\
\text { rays }\end{array}$ & $\begin{array}{l}\text { Head } \\
\text { length }\end{array}$ & $\begin{array}{l}\text { Caudal } \\
\text { peduncle } \\
\text { depth }\end{array}$ & $\begin{array}{l}\text { Anal } \\
\text { fin } \\
\text { base }\end{array}$ & $\begin{array}{l}\text { Anal } \\
\text { fin } \\
\text { height }\end{array}$ & $\begin{array}{l}\text { Dorsal } \\
\text { fin } \\
\text { base }\end{array}$ & $\begin{array}{l}\text { Dorsal } \\
\text { fin } \\
\text { height }\end{array}$ \\
\hline \multirow[t]{3}{*}{ IDH-1 } & Homo & 2405 & $1 \cdot 25$ & $0 \cdot 69$ & $17 \cdot 45$ & $10 \cdot 08$ & $24 \cdot 42$ & $32 \cdot 05$ & $23 \cdot 54$ & $54 \cdot 78$ \\
\hline & Hetero & 383 & $1 \cdot 30$ & 0.69 & $16 \cdot 57$ & $14 \cdot 36$ & $21 \cdot 66$ & $35 \cdot 19$ & $22 \cdot 48$ & $61 \cdot 22$ \\
\hline & $\mathrm{F}$ & & 0.96 & $1 \cdot 00$ & $1 \cdot 05$ & $0 \cdot 70$ & $1 \cdot 13$ & 0.91 & $1 \cdot 05$ & 0.89 \\
\hline \multirow[t]{3}{*}{ IDH-3 } & Homo & 1282 & $1 \cdot 23$ & 0.66 & $18 \cdot 39$ & $9 \cdot 20$ & $25 \cdot 64$ & $34 \cdot 84$ & $23 \cdot 64$ & $62 \cdot 31$ \\
\hline & Hetero & 1439 & $1 \cdot 26$ & 0.70 & $16 \cdot 78$ & $12 \cdot 09$ & $22 \cdot 53$ & $31 \cdot 74$ & $23 \cdot 33$ & $50 \cdot 55$ \\
\hline & $\mathrm{F}$ & & 0.98 & 0.94 & $1 \cdot 10$ & $0 \cdot 76$ & $1 \cdot 14^{*}$ & $1 \cdot 10$ & $1 \cdot 01$ & $1 \cdot 23^{*}$ \\
\hline \multirow[t]{3}{*}{$\mathrm{ME}$} & Homo & 1983 & $1 \cdot 24$ & 0.68 & $15 \cdot 84$ & $10 \cdot 72$ & $22 \cdot 71$ & $29 \cdot 47$ & $23 \cdot 34$ & $47 \cdot 89$ \\
\hline & Hetero & 802 & $1 \cdot 26$ & 0.70 & $21 \cdot 08$ & $10 \cdot 52$ & $27 \cdot 49$ & $41 \cdot 09$ & $23 \cdot 41$ & $73 \cdot 19$ \\
\hline & & & 0.98 & 0.97 & 0.75 & $1 \cdot 02$ & 0.83 & 0.72 & $1 \cdot 00$ & 0.65 \\
\hline \multirow[t]{3}{*}{$\mathrm{LGG}$} & Homo & 1963 & $1 \cdot 24$ & 0.68 & $18 \cdot 04$ & $10 \cdot 39$ & $24 \cdot 68$ & $37 \cdot 11$ & 23.93 & $60 \cdot 07$ \\
\hline & Hetero & 713 & $1 \cdot 23$ & 0.68 & $16 \cdot 50$ & $11 \cdot 44$ & $22 \cdot 74$ & $22 \cdot 43$ & $21 \cdot 69$ & $42 \cdot 13$ \\
\hline & $F$ & & $1 \cdot 01$ & $1 \cdot 00$ & $1 \cdot 09$ & 0.91 & $1 \cdot 09$ & $1.65^{*}$ & $1 \cdot 10$ & $1 \cdot 43^{*}$ \\
\hline \multirow[t]{3}{*}{ PMI } & Homo & 2129 & $1 \cdot 23$ & 0.68 & $17 \cdot 72$ & $10 \cdot 70$ & $23 \cdot 39$ & $26 \cdot 20$ & $22 \cdot 49$ & $41 \cdot 52$ \\
\hline & Hetero & 464 & $1 \cdot 18$ & 0.68 & $16 \cdot 86$ & $9 \cdot 85$ & $27 \cdot 50$ & $23 \cdot 41$ & $25 \cdot 70$ & $44 \cdot 11$ \\
\hline & $F$ & & $1 \cdot(04$ & $1 \cdot 00$ & 1.05 & 1.09 & 0.85 & $1 \cdot 12$ & 0.88 & 0.94 \\
\hline \multirow[t]{3}{*}{ AGP-2 } & Homo & 2350 & $1 \cdot 21$ & 0.67 & $17 \cdot 86$ & $11 \cdot 25$ & $23 \cdot 55$ & $.32 \cdot 18$ & $23 \cdot 23$ & $54 \cdot 88$ \\
\hline & Hetero & 219 & $1 \cdot 52$ & $0 \cdot 74$ & 16.69 & $9 \cdot 18$ & $27 \cdot 80$ & $45 \cdot 66$ & $23 \cdot 22$ & $81 \cdot 74$ \\
\hline & $\mathrm{F}$ & & $0 \cdot 80$ & 0.91 & $1 \cdot(17$ & $1 \cdot 23^{*}$ & 0.85 & $0 \cdot 70$ & $1 \cdot 00$ & 0.67 \\
\hline \multirow[t]{3}{*}{ Total } & Homo & 482 & $1 \cdot 28$ & 0.68 & $16 \cdot 29$ & $8 \cdot 25$ & $22 \cdot 63$ & $35 \cdot 21$ & $23 \cdot 00$ & 54.94 \\
\hline & Hetero & 2317 & $1 \cdot 23$ & 0.68 & $17 \cdot 72$ & $11 \cdot 15$ & $24 \cdot 19$ & $32 \cdot 51$ & $23 \cdot 40$ & $55 \cdot 66$ \\
\hline & $\mathrm{F}$ & & $1 \cdot 04$ & 1.00 & 0.92 & 0.74 & 0.94 & $1 \cdot 08$ & 0.98 & 0.99 \\
\hline
\end{tabular}


the group mean (and thus less morphologically variable) than were more homozygous salmon (all $P>0.05$ ) (table 2). The respective $F$ values for the 8 analyses of variance, all with 5 and 2803 degrees of freedom, were $1 \cdot 33,0.65,0.14,1.45$, $0 \cdot 39,1 \cdot 30,0 \cdot 59$ and $0 \cdot 37$. For each character considered separately, homozygous chum salmon were not more variable morphologically than were heterozygous ones.

We also compared chum salmon homozygous or heterozygous at each of the 7 most polymorphic loci for differences in variability for combined meristic and morphometric traits (table 3). On a locus by locus basis, homozygous chum salmon were not more variable than heterozygous ones for meristic characters ( $F$ values range from 0.00 to $1 \cdot 58, P>0 \cdot 05$ ). For the morphometric characters, homozygous and heterozygous chum salmon were equally variable at all loci except $M E$ (all $P>$ $0 \cdot 05$ ). Chum salmon homozygous for $M E$ were less variable morphometrically than were ones that were heterozygous $(F=6.05 ; \mathrm{df}=1$ and $2775 ; P<$ $0 \cdot 05)$. This was also true for $M E$ homozygotes and heterozygotes when all meristic and morphometric characters were combined $(F=6 \cdot 39, P<0 \cdot 05)$. For all characters combined, chum salmon homozygous and heterozygous at other loci had similar levels of phenotypic variability (all $P>$ $0 \cdot 05)$.

Finally, we compared mean levels of variability for meristic and morphometric characters among chum salmon with different numbers of heterozygous loci (table 4). There was no significant difference in levels of meristic variability for chum salmon having different numbers of heterozygous loci $(F=0.81: \mathrm{df}=5$ and $2803 ; P>0 \cdot 05)$. There were similarly no differences in morphometric variability $(F=0.58, P>0.05)$ or total variability $(F=$ $0 \cdot 50, P>0 \cdot 05)$ for chum salmon having different numbers of heterozygous loci. Thus, we found no relationship between heterozygosity at single loci or total number of heterozygous loci and degree of phenotypic variability in the chum salmon that were examined in this study.

We examined phenotypic variability and heterozygosity among chum salmon of different ages to detect any effects of stabilizing selection on phenotypic traits or genetic variability. There was no difference in the degree of meristic variability of chum salmon of different ages $(F=1 \cdot 21$, $\mathrm{df}=2$ and $2703, P>0.05)$. There was also no difference in the level of morphometric $(F=0 \cdot 03$,

Table 2 Mean Mahalanobis distance from population mean for chum salmon having different numbers of heterozygous loci. Ten loci were scored as homozygous or heterozygous. Standard deviations are in parenthesis. $\mathrm{N}$ is sample size

\begin{tabular}{|c|c|c|c|c|c|c|c|c|c|}
\hline \multirow{2}{*}{$\begin{array}{l}\text { No. of } \\
\text { heterozygous } \\
\text { Loci }\end{array}$} & \multirow[b]{2}{*}{$\mathrm{N}$} & \multicolumn{2}{|l|}{ Meristics } & \multicolumn{6}{|c|}{ Morphometrics } \\
\hline & & Gillrakers & $\begin{array}{l}\text { Branchiostegal } \\
\text { rays }\end{array}$ & Head length & $\begin{array}{l}\text { Caudal } \\
\text { peduncle }\end{array}$ & $\begin{array}{l}\text { Anal fin } \\
\text { base }\end{array}$ & $\begin{array}{l}\text { Anal fin } \\
\text { height }\end{array}$ & $\begin{array}{l}\text { Dorsal fin } \\
\text { base }\end{array}$ & $\begin{array}{l}\text { Dorsal fin } \\
\text { height }\end{array}$ \\
\hline 0 & 492 & $0.89(0.67)$ & $0.63(0.48)$ & $3 \cdot 12(2 \cdot 45)$ & $2 \cdot 22(1 \cdot 77)$ & $3.77(2 \cdot 92)$ & $4 \cdot 01(4 \cdot 14)$ & $3.81(2.91)$ & $4.94(5 \cdot 42)$ \\
\hline 1 & 1064 & $0.87(0.65)$ & $0.66(0.49)$ & $3 \cdot 14(2 \cdot 73)$ & $2 \cdot 41(2 \cdot 20)$ & $3 \cdot 72(3 \cdot 11)$ & $3.83(3.77)$ & $3.71(3.02)$ & $4.97(4.88)$ \\
\hline 2 & 845 & $0.89(0.65)$ & $0.65(0.47)$ & $3.08(3.02)$ & $2 \cdot 25(2 \cdot 30)$ & $3.83(3.00)$ & $4 \cdot 15(4 \cdot 80)$ & $3 \cdot 70(3 \cdot 13)$ & $5 \cdot 17(6.65)$ \\
\hline 3 & 343 & $0.92(0.65)$ & $0.64(0.49)$ & $3 \cdot 15(2 \cdot 29)$ & $2 \cdot 56(2 \cdot 70)$ & $3.97(3.03)$ & $3.78(3.03)$ & $3.55(2.94)$ & $4.91(3.67)$ \\
\hline 4 & 58 & $0.81(0.66)$ & $0.74(0.62)$ & $3 \cdot 10(2 \cdot 05)$ & $2 \cdot 44(1.86)$ & $3 \cdot 64(3 \cdot 23)$ & $3 \cdot 38(2 \cdot 82)$ & $4 \cdot 15(3 \cdot 40)$ & $5 \cdot 27(3 \cdot 46)$ \\
\hline 5 & 7 & $1.40(0.53)$ & $0.67(0.60)$ & $3.79(2.43)$ & $2 \cdot 00(1 \cdot 24)$ & $3.70(3.06)$ & $1.89(1.66)$ & $3 \cdot 17(3 \cdot 16)$ & $3 \cdot 27(1 \cdot 87)$ \\
\hline
\end{tabular}

Table 3 Mean Mahalanobis distance from population centroid for chum salmon homozygous and heterozygous at 7 loci. Two meristic and six morphometric characters were included in the determination of Mahalanobis distance. Standard deviations are in parenthesis

\begin{tabular}{|c|c|c|c|c|c|c|c|c|}
\hline \multirow[b]{2}{*}{ Locus } & \multirow[b]{2}{*}{$\mathrm{N}$} & \multirow[b]{2}{*}{ Homozygous } & \multicolumn{2}{|c|}{ Meristics } & \multicolumn{2}{|c|}{ Morphometrics } & \multicolumn{2}{|l|}{ Total } \\
\hline & & & $\mathrm{N}$ & Heterozygous & Homozygous & Heterozygous & Homozygous & Heterozygous \\
\hline IDH-1 & 2405 & $1 \cdot 20(0 \cdot 66)$ & 383 & $1 \cdot 18(0.64)$ & $10.99(6 \cdot 21)$ & $11 \cdot 09(6 \cdot 96)$ & $12 \cdot 20(6 \cdot 24)$ & $12 \cdot 28(6 \cdot 97)$ \\
\hline 1DH-3 & 1282 & $1 \cdot 19(0.65)$ & 1439 & $1 \cdot 21(0.65)$ & $11 \cdot 13(6 \cdot 82)$ & $10.91(5.90)$ & $12 \cdot 32(6 \cdot 84)$ & $12 \cdot 13(5 \cdot 93)$ \\
\hline AGP-2 & 2457 & $1.19(0.64)$ & 219 & $1.25(0.73)$ & $10 \cdot 97(6 \cdot 26)$ & $11 \cdot 50(7 \cdot 70)$ & $12 \cdot 17(6 \cdot 29)$ & $12 \cdot 76(7 \cdot 67)$ \\
\hline $6-P G$ & 2785 & $1.20(0.65)$ & 19 & $1.28(0.52)$ & $11 \cdot 00(6 \cdot 32)$ & $10 \cdot 60(4 \cdot 26)$ & $12 \cdot 21(6 \cdot 34)$ & $11 \cdot 86(12 \cdot 20)$ \\
\hline $\mathrm{ME}$ & 1979 & $1 \cdot 20(0.65)$ & 798 & $1 \cdot 22(0.66)$ & $10.82(5.53)$ & $11.47(7.91)$ & $12: 02(5 \cdot 56)$ & $12 \cdot 69(7 \cdot 91)$ \\
\hline PMI & 2327 & $1.20(0.66)$ & 469 & $1 \cdot 19(0.65)$ & $11.00(6.59)$ & $11 \cdot 03(4 \cdot 75)$ & $12 \cdot 21(6 \cdot 61)$ & $12 \cdot 22(4 \cdot 79)$ \\
\hline $\mathrm{LGG}$ & 1963 & $1.20(0.66)$ & 713 & $1 \cdot 19(0.65)$ & $11 \cdot 14(6 \cdot 85)$ & $10 \cdot 64(4 \cdot 70)$ & $12 \cdot 34(6 \cdot 87)$ & $11 \cdot 94(4 \cdot 74)$ \\
\hline
\end{tabular}


Table 4 Mean Mahalanobis distance from population centroid for chum salmon with different numbers of heterozygous loci for 2 meristic, 6 morphometric, and 8 characters in total. Standard deviations are in parenthesis

\begin{tabular}{lrlll}
$\begin{array}{l}\text { No. of } \\
\text { heterozygous } \\
\text { loci }\end{array}$ & $\mathrm{N}$ & Meristics & Morphometrics & Total \\
\hline 0 & 492 & $1 \cdot 20(0 \cdot 65)$ & $10.92(6 \cdot 10)$ & $12 \cdot 12(6 \cdot 15)$ \\
1 & 1064 & $1 \cdot 19(0 \cdot 66)$ & $10 \cdot 87(5 \cdot 79)$ & $12 \cdot 06(5 \cdot 83)$ \\
2 & 845 & $1 \cdot 20(0.65)$ & $11 \cdot 27(7 \cdot 76)$ & $12 \cdot 47(7 \cdot 74)$ \\
3 & 343 & $1 \cdot 22(0 \cdot 66)$ & $10 \cdot 91(4 \cdot 13)$ & $12 \cdot 13(4.25)$ \\
4 & 58 & $1 \cdot 22(0 \cdot 70)$ & $10.96(3 \cdot 76)$ & $12 \cdot 18(3 \cdot 84)$ \\
5 & 7 & $1.67(0.47)$ & $8 \cdot 82(2 \cdot 77)$ & $10 \cdot 49(3 \cdot 10)$ \\
\hline
\end{tabular}

Table 5 Mean Mahalanobis distance from population centroid and heterozygosity based upon 10 loci for chum salmon of different ages. Standard deviations are in parenthesis

\begin{tabular}{lrllll}
\hline Age & $N$ & Meristics & Morphometrics & Total & Heterozygosity \\
\hline 3 & 763 & $1 \cdot 17(0.65)$ & $10.94(6.73)$ & $12 \cdot 12(6.75)$ & $0 \cdot 146(0 \cdot 102)$ \\
4 & 1702 & $1 \cdot 21(0.65)$ & $11 \cdot 00(6.00)$ & $12 \cdot 21(6.04)$ & $0 \cdot 145(0 \cdot 100)$ \\
5 & 241 & $1.17(0.64)$ & $10.92(7.62)$ & $12.09(7.62)$ & $0 \cdot 139(0.091)$ \\
\hline
\end{tabular}

$P>0.05)$ or total variability $(F=0.08, P>0.05)$ among age groups (table 5). Stabilizing selection for these traits, over the age groups examined, was not apparent in the chum salmon populations of this study. Similarly, no effect of selection on genotypes was apparent; the level of heterozygosity was similar among ages $(F=0.45, P>0.05)$.

\section{Population Heterozygosity and Morphology Variance}

We compared the relative degree of variation of morphometric and meristic characters with the level of heterozygosity in a population. Chum salmon populations that had higher levels of heterozygosity also has a greater variability for morphometric characters (fig. 2), but not for meristic ones (fig. 3). Heterozygosity and morphometric variability were significantly correlated for both males $(r=0.49, \mathrm{df}=25, P<0.05)$ and females $(r=$ 0.39 , $\mathrm{df}=25, P<0.05)$, and for both sexes combined $(r=0 \cdot 42, \mathrm{df}=52, P<0 \cdot 05)$. Morphometric characters were relatively more variable than meristic ones, with the mean coefficient of variation for the meristic characters less than 7 per cent in all populations. Populations that were more heterozygous were all more variable morphometrically.

We compared genetic distance between all pairwise combinations of populations with Mahalanobis distance based upon all morphometric characters and all meristic characters. There was no relationship between genetic distance

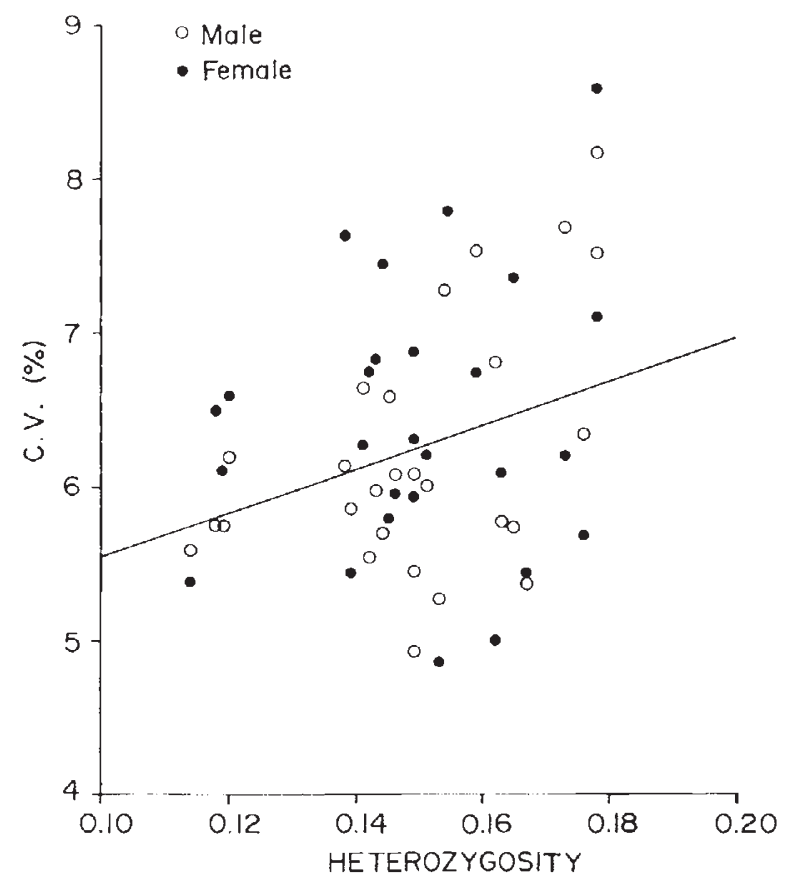

Figure 2 Relationship between the mean coefficient of variation pooled over six morphometric characters and heterozygosity for'male and female chum salmon in 27 populations in southern British Columbia.

and Mahalanobis distance when the morphometric characters were considered (figs. 4 and 5). In particular, the genetic distance between populations was not correlated with Mahalanobis distance for either males $(r=-0.08, \mathrm{df}=349, P>0.05)$ or 


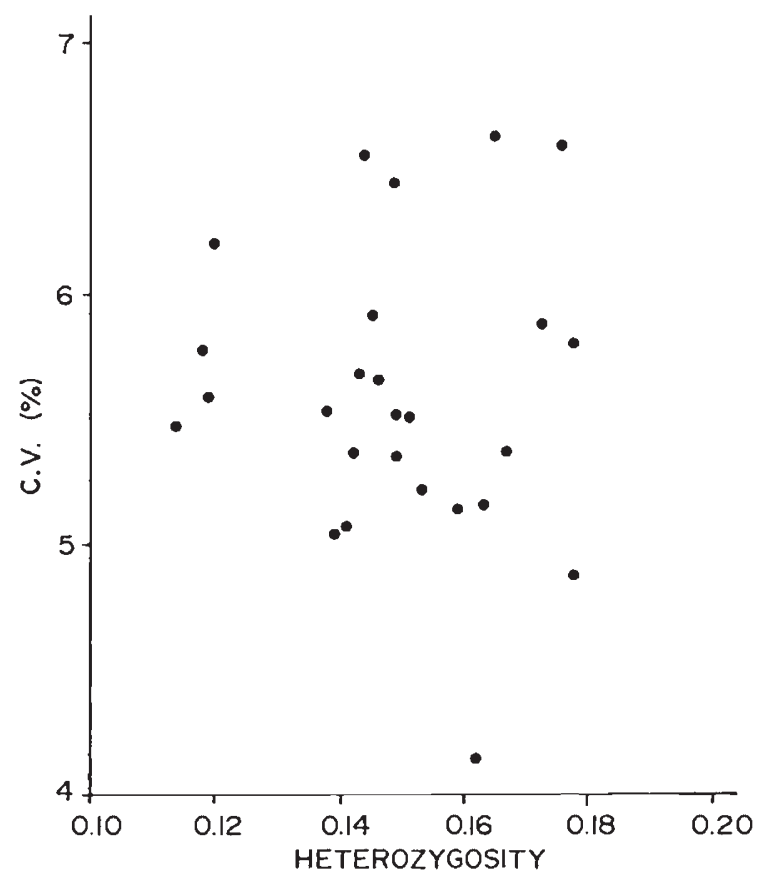

Figure 3 Relationship between the mean coefficient of variation pooled over two meristic characters and heterozygosity for 27 chum salmon populations.

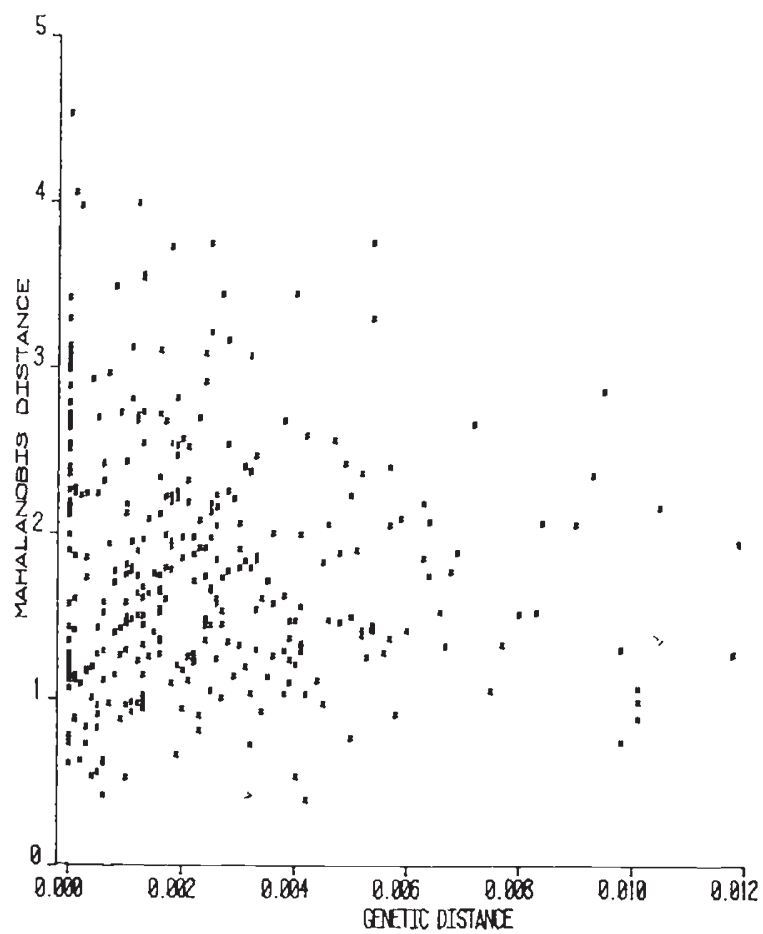

Figure 4 Mahalanobis distance for morphometric characters versus genetic distance for all pairwise combinations of males in 27 chum salmon populations.

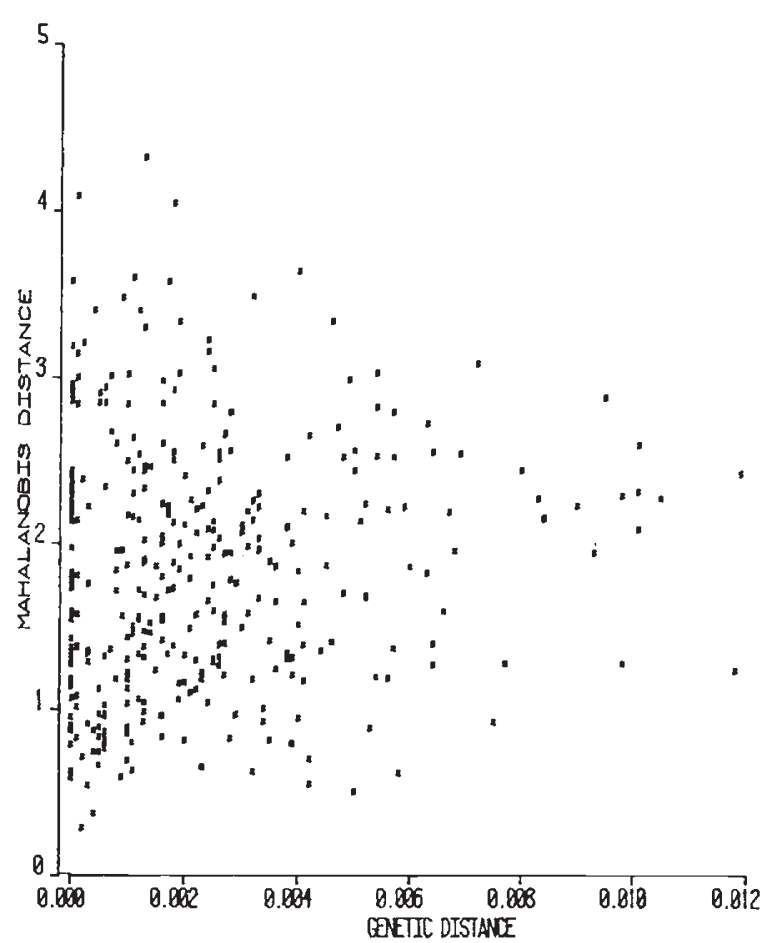

Figure 5 Mahalanobis distance for morphometric characters versus genetic distance for all pairwise combinations of females in 27 chum salmon populations.

females $(r=0.09, \mathrm{df}=349, P>0.05)$. As genetic distance between poluations increased, Mahalanobis distance based upon meristic characters also increased (fig. 6), with the correlation being significant $(r=0 \cdot 17, \mathrm{df}=349, P<0.01)$. As populations became more similar in their allelic frequencies, they also tended to become more similar in the mean number of gillrakers and branchiostegal rays.

\section{DISCUSSION}

We demonstrated no relationship between morphological variability and levels of heterozygosity for chum salmon in southern British Columbia. There was no reduction in phenotypic variance that could be attributed to genetic homeostasis in chum salmon with comparatively more heterozygous loci. Morphological variability did not decrease with age in adult chum salmon, nor did heterozygosity increase with age. Both trends might be observed if morphological variability in chum was subject to stabilizing selection, and if high levels of heterozygosity contributed to a canalisation of morphology during development. 


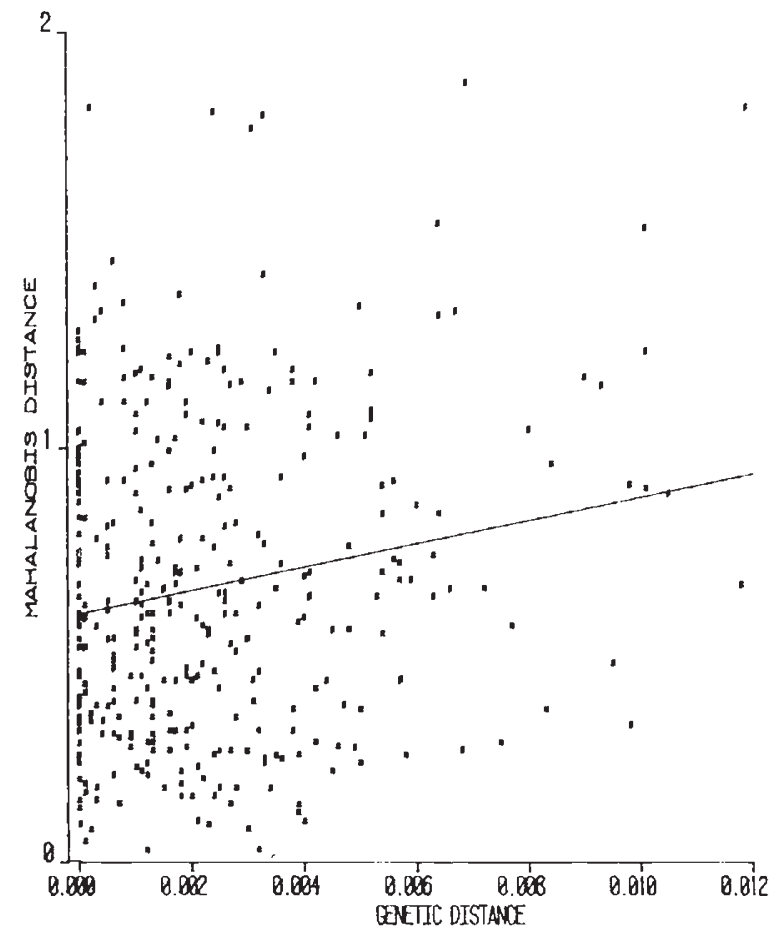

Figure 6 Mahalanobis distance for meristic characters versus genetic distance for all pairwise combinations of 27 chum salmon populations.

The absence of a relationship between morphological variability and heterozygosity for individuals is not surprising in view of our small sample of the thousands of loci that constitute the chum salmon genome. Electrophoretic screening of ten, or even one hundred, loci does not provide an estimate of overall genomic heterozygosity unless there exists a large amount of linkage disequilibrium among loci. Pairwise tests of allelic associations among the chum salmon loci examined in this study revealed no significant linkage disequilibrium (Beacham et al., 1985). The relating of genetic to phenotypic variance is made more difficult by a consideration of regulatory loci, which control gene expression and exert a strong influence upon development. The consequences of heterozygosity at regulatory loci, whose proteins products, when they exist, are not screened by electrophoresis, may be disproportionately great (Johnson, 1977; Wilson, 1977). Levels of heterozygosity over the entire genome may affect morphological variability less than the level of heterozygosity at a relatively few, but important loci, that control gene expression. Finally, our inability to relate the activity of any one gene product (enzyme) to a single morphological trait, or to assess the magnitude of epistatic and genotype environment interactions on morphological variability further obscures the relationship between phenotypic and genetic variability.

Allelic variation at the Pgml-t regulatory locus in another salmonid species, the rainbow trout (Salmo gairdneri), has been shown to influence developmental rates, meristic symmetry and age of maturity (Allendorf et al., 1983). Moreover, rainbow trout of differing Pgml-t genotypes also differed in eight meristic characters, presumably as a result of the influence of Pgm 1-t on development rate (Leary et al., 1984). However, in spite of this convincing demonstration of the great effects that may be associated with variation at a single regulatory locus, Allendorf et al. also found that average heterozygosity over 42 structural (enzyme) loci was associated with greater developmental stability, as measured by meristic symmetry, in rainbow trout and two other salmonid species.

Mitton and Koehn (1975) correlated allelic frequencies in killifish populations with environmental variables, and documented sex- and agespecific changes in allelic and genotypic frequencies. This genetic variability was attributed to selection and Mitton (1978), in his demonstration of a relationship between heterozygosity and morphological variability in killifish, provided the mechanism by which genotypic frequencies might be altered by stabilizing selection on morphological traits. An increase of heterozygosity with size has also been reported in the bleak, Alburnus alburnus, (Handford, 1983), and a decrease in tuna, Katswonus pelamis (Fujino and Kang, 1968), but morphological variability was not monitored in these studies.

McAndrew et al. (1982) reported no relationship between levels of heterozygosity and morphological variability in plaice. There was no strong evidence for the action of stabilizing selection on plaice morphology over the age groups examined, and the authors suggested that an association between heterozygosity and morphological variance may be more likely apparent when selection can be shown to be operating on phenotypic characters.

The apparent absence of stabilizing selection on morphological variability in chum salmon may be real, or may be due to the fact that juvenile age classes were not surveyed. Selection may remove phenotypically extreme salmon from the population before adulthood. Similarly, the prevalence of Hardy-Weinberg equilibrium at individual loci and linkage equilibrium between pairs of loci in 
chum salmon populations (Beacham et al., 1985), coupled with a constancy of allelic frequencies and heterozygosity over adult age classes, is suggestive of a lack of selection on electrophoretic variability. However, in some species, Hardy-Weinberg genotypic frequencies in adults apparently arise from juvenile non-equilibrium genotypic frequencies through selection (Fujino and Kang, 1968; Handford, 1983). Thus, with our data we cannot rule out the possibility that selection may affect both phenotypic and genetic variance in juvenile chum salmon.

Regardless of whether or not the observed levels of heterozygosity in the chum salmon populations surveyed are due to natural selection or to stochastic events, we assume that the loci screened in this study reflect relative levels of heterozygosity at biochemical loci among populations. The fact that morphometric variability did not decrease, but actually increased, in more heterozygous populations indicates that increased levels of heterozygosity at biochemical loci do not reduce phenotypic variability by dampening the environmental component. The actual increase in morphological variability in more heterozygous populations may indicate that increased variability at electrophoretic loci is correlated with increased variability at the loci determining morphometric characters. The increased phenotypic variability in this case would be due to an increased genetic contribution.

Kijima and Fujio (1984) found that average heterozygosity is related to effective population size in Japanese chum salmon populations. If this is also true for the chum populations of our study, the positive correlation between biochemical and morphological variation may simply result from decreased genetic drift, and therefore increased genetic variance, in populations with large effective sizes. Bryant (1984) attributed a correlation between levels of biochemical and morphological variability in the face fly (Musca autumnalis) to genetic drift during a population bottleneck. It is possible that the positive correlation between average heterozygosity and morphological variation in island populations of the lizard (Uta stansburiana) reported by Soulé et al. (1973) is also due to variability in the long term effective population sizes of lizards on different islands.

We found a significant correlation between pairwise genetic distance and pairwise Mahalanobis distance based on meristic characters for the chum salmon populations surveyed in this study. In a survey of electrophoretic, meristic, and morphometric characters in lake whitefish
Coregonus clupeaformis, Ihssen et al. (1981) also found a correlation between Mahalanobis distance for the meristic variation and genetic distance for the electrophoretic variation. The morphometric characters surveyed in out study have previously been shown to be adapted to environmental conditions that the returning adult chum salmon encounter in their natal streams (Beacham, 1984) so that chum salmon spawning in large rivers and small creeks in close proximity to each other will be different morphometrically. Allelic frequencies and meristic frequencies of chum salmon spawning at similar times in dissimilar rivers in close proximity are similar, and appear to be less affected by differential selection among habitats than the morphometric characters.

Acknowledgments The extensive field sampling for this research was conducted by several people. Among those participating were Gerry Buxton, Terry Calvin, Morley Farwell, Al Gould, Claudia Hand, Clyde Murray, Alvin Sewid, Alf Stefanson, and Peter Withler. The electrophoretic analysis was conducted under contract to the Department of Fisheries and Oceans by Helix Biotech Ltd of Richmond, British Columbia.

\section{REFERENCES}

ALLENDORF, F. W., KNUDSEN, K. L. AND LEARY, R. F. 1983 Adaptive significance of differences in the tissue-specific expression of a phosphogluco-mutase gene in rainbow trout. Proc. Natl. Acad. Sci. USA, 80, 1397-1400.

ANGUS, R. A. AND SCHULTZ, R. J. 1983. Meristic variation in homozygous and heterozygous fish. Copeia 1983(2), 287299.

BEACHAM, T. D. 1984. Age and morphology of chum salmon (Oncorhynchus keta) in southern British Columbia. Trans. Amer. Fish. Soc., 113, 727-736.

BEACHAM, T. D., GOULD, A. P. AND STEFANSON, A. P. 1983. Size, age, meristics, and morphometrics of chum salmon returning to southern British Columbia during 1981-1982. Can. Tech. Rep. Fish. Aquat. Sci., No. 1207: 37 pp.

BEACHAM, T. D. AND MURRAY, C. B.1983. Sexual dimorphism in the adipose fin of Pacific salmon (Oncorhynchus). Can. J. Fish. Aquat. Sci., 40, 2019-2024.

BEACHAM, T. D. AND STARR, P. 1982. Population biology of chum salmon, Oncorhynchus keta, from the Fraser River, British Columbia. Fish. Bull., 80, 813-825.

BEACHAM, T. D., WITHLER, R. E. AND GOULD. A. P. 1985. Biochemical genetic stock identification of chum salmon (Oncorhynchus keta) in southern British Columbia. Can. J. Fish. Aquat. Sci., 42, 437-448.

B1LTON, H. T. AND R1CKER, W. E. 1965. Supplementary checks on the scales of pink salmon (Oncorhynchus gorbuscha) and chum salmon (O. keta). J. Fish. Res. Board Can., 22, $1477-1489$.

BRYANT, E. H. 1984. A comparison of electrophoretic and morphometric variability in the face fly, Musca autumnalis. Evolution, 38, 455-458.

EANES, W. F. 1978. Morphological variance and enzyme heterozygosity in the monarch butterfly. Nature, 276, 263264 . 
FUJINO, K. AND KANG, T. 1968. Transferrin groups in tunas. Genetics, 59, 79-91.

GOULD, S. J. 1966. Allometry and size in ontogeny and phylogeny. Biol. Rev., 41, 587-640.

HANDFORI, P. 1980. Heterozygosity at enzyme loci and morphological variation. Nature, 286, 261-262.

HANDFORD, P. 1983. Age-related allozymic variation in the cyprinid fish Alburnus alburnus. Can. J. Zool., 61, 28442848.

IIUBBS, C L. AND LAGLFR, K. F. 1958. Fishes of the Great Lakes region. Cranbrook Inst. Sci. Bull, No. 26, 213pp.

IHSSEN, P. F., IVVANS, D. O., CHRISTIF, W. J., RECKAHN, J. A. AND DES.IARIMINE, R. L. 1981. Life history, morphology, and electrophoretic characteristics of five allopatric stocks of lake whitefish (Coregonus clupeaformis) in the Great Lakes region. Can. J. Fish. Aquat. Sci., 38, 1790-1807.

JOHNSON, G. B. 1977. Genetic polymorphism and enzyme function. In Ayala F. J. (ed) Molecular Evolution, Sinauer Associates Inc., pp. 46-59.

KINDALL, M. 1975. Multivariate Statistical Analyses. Hafner Press, New York.

KIJIMA, A. ANI) FUJIO, Y. 1984. Relationship between average heterozygosity and river population size in chum salmon. Bull. Jap. Soc. Sci. Fish., 50, 603-608.

KOF.HN, R. K. 1970. Functional and evolutionary dynamics of polymorphic esterases in catostomid fishes. Trans. Amer. Fish. Soc., 99, 219-228.

LALANNE, J. J. AND SAFSTEN, (i. 1969. Age determination from scales of chum salmon (Oncorhynchus keta). J. Fish. Res Board Can., 26, 671-681.

LEARY, R. F., ALLFNDORF, F. W. ANI) KNUIDSEN, K. L. 1984. Major morphological effects of a regulatory gene: Pgm I-t in rainbow trout. Mol. Biol. Evol., 1, 183-194.

L.R RF:R, I. M. 1954. Genetic Homeostasis. Oliver and Boyd, London.

MCANDREW, B. J. WAR!), R. D. AND BEARDMORE, J. A. 1982. Lack of relationship between morphological variance and enzyme heterozygosity in the plaice, Pleuronectes platessa. Heredity, 48, $117-125$.

MITTON. J. B. 1978. Relationship between heterozygosity for enzyme loci and variation of morphological characters in natural populations. Nature, 273, 661-662.

MITTON, J. B. AND KOHHN, R. K. 1975. Genetic organization and adaptive responses of allozymes to ecological variables in Fundulus heteroclitus. Genetics, 79, 97-111.

NE1, M. 1978. Estimation of average heterozygosity and genetic distance from a small number of individuals. Genetics, 89 , $583-590$.

RICKER, W. E. 1980. Changes in the age and size of chum salmon (Oncorhynchus keta). Can Tech. Rep. Fish. Aquat. Sci. 930, 99pp.

soui .́, M. I: 1979. Heterozygosity and developmental stability: another look. Evolution, 33, 396-401

SOULÉ, M. E., YANG, S. Y., WIiller, M. G. W. AND GORMAN, G. (C. 1973. Island lizards: the genetic-phenetic variation correlation. Nature, 242, 191-193.

THORPE, R. S. 1976. Biometrical analysis of geographic variation and racial affinities. Biol. Rev., 51, 407-452.

UTTER, F. M., HODGINS, H. O. ANI) ALLENDORF, F. W. 1974. Biochemical genetic studies of fishes: potentialities and limitations. In Malins, D. (ed.) Biochemical and Biophysical Perspectives in Marine Biology, Vol. I, Academic Press, San Franscisco, pp. 213-237.

VI.ADYKov, V. D. 1962. Osteological studies on Pacific salmon of the genus Oncorhynchus. Bull. Fish. Res. Board Can., $136,171 \mathrm{pp}$.

WILSON, A. C. 1977. Gene regulation in evolution. In Ayala, F. J. (ed.) Molecular Evolution, Sinauer Associates Inc., pp. 225-234.

YOSHIYAMA, R. M. AND SASSAMAN, C. 1983. Morphological and allozymic variation in the stichaeid fish Anoplarchus purpurescens. Syst. Zool., 32, 52-71. 